\author{
${ }^{1}$ Shidqi Alia Taufiq dan ${ }^{2}$ Ratri Wulandari \\ Program Studi Desain Interior \\ Universitas Telkom \\ 'shidqi.alia@gmail.com \\ ${ }^{2}$ ratriwulandari@tcis.telkomuniversity.ac.id
}

\title{
EFEKTIVITAS LOKASI PENEMPATAN PAPAN PETUNJUK (SIGNAGE SYSTEM) PADA LOBBY STASIUN KERETA API BANDUNG
}

\begin{abstract}
Abstrak: Salah satu transportasi umum yang saat ini diminati masyarakat adalah kereta. Adanya peningkatan pelayanan pada transportasi ini, merupakan salah satu faktor meningkatnya minat masyarakat untuk menggunakannya. Adanya peningkatan peminat pengguna kereta ini juga harus diikuti dengan meningkatnya pelayanan di stasiun kereta. Pada stasiun kereta dibutuhkan fasilitas-fasilitas yang memudahkan calon penumpang agar dapat melakukan perjalanan dengan semestinya. Salah satu fasilitas yang perlu diperhatikan yaitu berkaitan dengan informasi yang dibutuhkan pengunjung dan penumpang ketika berada di stasiun kereta. Informasi yang ingin didapatkan pengunjung dan penumpang sangat beragam, mulai dari tata cara beli tiket, penukaran tiket, jadwal keberangkatan kereta, letak ruang tunggu, letak peron yang akan dituju, hingga letak toilet dan mushola.

Salah satu sarana informasi yang efektif digunakan yaitu papan petunjuk atau signage system. Signage merupakan sebuah sarana informasi yang mengarahkan manusia pada sebuah tempat dan membantunya untuk mencapai tempat tersebut. Stasiun Kereta Bandung merupakan stasiun kereta besar di Jawa Barat yang menerapkan papan petunjuk atau signage system sebagai salah satu sarana informasi yang ditujukan bagi pengunjung maupun penumpang yang dipasang di beberapa sudut lobby dari Stasiun Kereta Bandung. Meski demikian, masih banyak pengunjung yang bertanya kepada petugas mengenai informasi tertentu yang sebenarnya sudah ditampilkan pada signage system. Hal ini terjadi dikarenakan beberapa faktor, salah satu faktor tersebut ialah lokasi penempatan papan petunjuk atau signage system yang kurang tepat.

Penelitian ini dilakukan dengan metoda campuran kualitatif dan kuantitatif, dengan menggunakan observasi, dokumentasi, wawancara, dan studi pustaka dalam pengumpulan data. Kesimpulan diperoleh melalui analisis terhadap sirkulasi penumpang dan pengunjung untuk memperoleh titik lokasi penempatan signage system yang efektif di Lobby utama Stasiun Bandung. Diharapkan, dengan artikel penelitian mengenai keefektifan lokasi penempatan signage system di lobby Stasiun Kereta Bandung ini dapat memberikan informasi yang membantu pihak Stasiun Kereta Bandung dalam memaksimalkan pelayanannya terhadap pengunjungnya terkait penyampaian informasi dalam sebuah ruang interior.
\end{abstract}

Kata kunci: signage, stasiun, sistem

Abstract: One of favorite public transportation at present days is train. The increasing level of services becomes one factor that drives public interest to use this transportation. Based on this fact, the increase of passengers should be followed with the service enhancement at train station. Train station required facilities which can facilitate all passengers to travel properly. One facilities to be considered is the information facilities required by both passengers and visitors. Informations needed by both passengers and visitors are diverse. Visitors and passengers need a guide to buy a ticket, location of ticket exchange counter, train departure schedules, location of passenger service, location of platforms, location of toilets and prayer room.

One of the information tool that used to be effective is signage system. Signage is an information tool that leads and helps people to reach their destination. Bandung Train Station is a major train station in West Java that uses signage systems as their information tools that informs both passengers and visitors every informations they need, placed at some corners in main lobby of Bandung Train Station. Nevertheless, there are still many visitors asking the employee about specific informations they need although it has already displayed on the 
signage systems. This case happens due to some factors. One of the factors is ineffectivity of the placement location of the signage.

This research is conducted using mixed qualitative and qualitative method, applying observation, documentation, interviews, and literature in data collection. Conclusion is obtained through analysis of passengers and visitors circulations to acquire a more effective location for signage system placement in Bandung Train Station's main lobby. research is expected to provide information that helps Bandung Train Station's management to enhance its passengers' service related to information distribution within an interior space.

Keywords: signage, station, system

\section{Pendahuluan}

Salah satu transportasi umum yang saat ini diminati masyarakat adalah kereta, dengan tersedianya berbagai jenis kereta yang dapat mengantar penumpang dari satu kota ke kota lainnya dengan beberapa pilihan kelas/golongan yang dapat dipilih sendiri oleh calon penumpang merupakan faktor meningkatnya minat masyarakat untuk menggunakan salah satu transportasi umum ini. Respon baik tersebut, sebaiknya dibarengi dengan ditingkatkannya pelayanan stasiun kereta.

Kriteria ruang publik yang efektif, menurut Carr, et.al. (1992) setidaknya meliputi tiga hal, yaitu responsif, demokratis, dan bermakna. Responsif maksudnya memenuhi kebutuhan bagi setiap individu, demokratis artinya dapat memberikan perlindungan terhadap hak-hak individu di dalamnya, serta bermakna maksudnya adalah dapat memberikan kesempatan bagi individu untuk berhubungan dengan lingkungan yang luas. Berdasarkan pernyataan tersebut, maka dapat disimpulkan bahwa kepentingan individu baik dari penumpang, calon penumpang, bahkan pengantar yang ada di stasiun kereta merupakan hal-hal yang menjadi prioritas utama pada suatu ruang publik.

Kebutuhan-kebutuhan individu di stasiun kereta yang harus dipenuhi dengan baik di antaranya, tersedianya fasilitas-fasilitas standar pelayanan stasiun kereta api yakni pelayanan customer service, sarana ibadah, toilet, dan fasilitas penjualan tiket. Salah satu sarana lainnya yang wajib disediakan adalah sarana informasi yang informatif yang dapat menyampaikan langsung berita pada pengunjung. Jika melihat dari sarana informasi yang ada pada stasiun kereta, maka sarana dapat berupa counter informasi dan papan petunjuk (signage system) yang dipasang di sejumlah titik pada stasiun kereta.

Stasiun Kereta Api Bandung memiliki sarana informasi (terutama signage system) berupa layar LCD yang menayangkan jadwal kereta yang akan berangkat dan petunjuk lokasi ruangan. Dengan sudah tersedianya signage system tersebut, bukan berarti informasi yang diinginkan pengunjung sudah terpenuhi. Hal ini terbukti dengan masih banyaknya pengunjung yang bertanya kepada petugas mengenai informasi yang sebenarnya sudah 
dipasang pada signage system Stasiun Kereta Api Bandung. Hal ini terjadi karena berbagai faktor, salah satunya yaitu titik lokasi penempatan dari papan petunjuk (signage system) yang kurang strategis sehingga kurang disadari oleh pengunjung.

Dengan menggunakan metode campuran yakni kualitatif dan kuantitatif, menggunakan beberapa metode pengumpulan data antara lain observasi alur sirkulasi pengunjung, wawancara dan pengisian kuesioner oleh pengunjung mengenai signage system Stasiun Kereta Bandung, studi literatur, serta dokumentasi, penelitian ini diharapkan dapat memecahkan masalah terkait pelayanan stasiun kereta terutama dalam hal sarana informasi. Berdasarkan latar belakang tersebut, permasalahan yang menjadi fokus dalam penelitian ini adalah seberapa besar efektivitas lokasi penempatan papan petunjuk (signage system) di lobby Stasiun Kereta Api Bandung.

\subsection{Stasiun Kereta Api Bandung}

Stasiun Kereta Api Bandung atau Stasiun Hall (BD), adalah stasiun kereta api utama dan terbesar di Jawa Barat. Stasiun yang terletak di $+709 \mathrm{~m}$ ini sebelumnya hanya memiliki satu buah stasiun, Setelah dilakukan renovasi oleh pemerintah maka Stasiun Bandung sekarang terbagi menjadi stasiun utara dan selatan. Stasiun Bandung berlokasi di Jalan Stasiun Timur No. 1 (pintu selatan) dan Jalan Kebon Kawung No. 43 (pintu utara), Kota Bandung. Stasiun Bandung memiliki 6 jalur utama yang sering dijadikan tempat pemberhentian kereta api-kereta api kelas eksekutif, bisnis, dan campuran.

\subsection{Lobby \& Sarana Informasi Stasiun Kereta Api Bandung}

Fokus studi pada penelitian ini adalah lobby pintu utara Stasiun Bandung. Untuk menuju lobby pintu utara Stasiun Bandung terdapat beberapa akses, diantaranya yaitu dari pintu utama (utara), pintu barat, dan pintu timur. Di tengah-tengah lobby ini terdapat area duduk untuk pengunjung/penumpang yang terbagi di dua sisi, yaitu sisi barat dan timur. Selain area duduk, akses dari lobby ini juga terhubung langsung ke beberapa ruang, diantaranya loket, pemeriksaan tiket, customer service, retail, dan atm center. Selain ruangruang yang terhubung langsung, juga terdapat ruang yang tidak terhubung langsung, seperti toilet dan mushola. 


\section{Kajian Literatur}

Signage System merupakan bagian dari EGD atau Enviromental Graphic Design. EGD dapat dijelaskan sebagai informasi yang berupa komunikasi grafis dalam membentuk sebuah lingkungan. Dalam penerapannya, EGD ini berhubungan dengan bidang ilmu arsitektur, lansekap, interior, dan desain industri. Chris Calori (2007), membagi EGD menjadi tiga jenis, yaitu:

- Signage dan Wayfinding, yaitu sign yang biasanya terprogram untuk mengarahkan manusia pada sebuah tempat dan membantunya untuk mencapai tempat tersebut

- Interpretation, yaitu informasi yang menceritakan kisah/cerita suatu tempat

- Placemaking, yaitu berupa informasi yang bertujuan membuat image khusus dari suatu tempat.

Menurut Craig M. Berger (2005) sign pada umumnya dibagi menjadi tujuh kategori, di antaranya:

- Identification Sign: sign yang berfungsi untuk mengidentifikasikan suatu area dalam sebuah lingkungan dan menunjukan lokasi dimana pengguna itu berada saat ini

- Directional Sign: sign yang ditempatkan pada suatu lokasi untuk memandu seseorang ketempat yang ingin ditujunya. Directional sign terkadang juga dikenal dengan wayfinding

- Warning Sign: sign yang bertujuan untuk mengingatkan seseorang tentang peringatan atau prosedur keselamatan dari sebuah lingkungan

- Regulatory dan Prohibitory Sign: sign yang mengatur regulasi mengenai aktivitas tertentu pada lingkungan tersebut

- Operational signs: sign yang memberikan informasi tentang cara penggunaan, yang di dalamnya berisi sistem operasional

- Honorific Sign: sign yang dibuat untuk sebuah penghormatan kepada sosok yang terkait dalam pembangunan maupun keberlangsungan suatu lingkungan.

- Interpretative Sign: berisi informasi untuk membantu seseorang untuk memahami suatu lingkungan terkait sejarah, geografi, artefak, dan lain-lain.

Peraturan Menteri Perhubungan RI (PM. 47 tahun 2014) mengenai standar pelayanan minimum di stasiun kereta api menyatakan bahwa informasi dalam bentuk visual, harus ditempatkan di tempat yang strategis, mudah dilihat, serta dapat dibaca jelas oleh jangkauan penglihatan pengguna jasa.

Pembuatan Sign yang baik menurut Sumbo Tinarbuko (2008) adalah harus memenuhi empat kriteria berikut:

- Mudah Dilihat

Penempatan sign juga harus dipikirkan secara tepat. Dan penempatan sign yang baik yaitu ditempat yang mudah diakses orang.

- Mudah Dibaca

Bentuk huruf atau tipografi yang digunakan dalam sign. Sebisa mungkin dapat terbaca.

- Mudah Dimengerti 
Bentuk penulisan yang tertera pada sign harus mudah untuk dipahami. Bentuk tulisan juga sebisa mungkin singkat dan padat.

- Dapat Dipercaya

Kebenaran informasi yang ada dapat dipercaya tidak menyesatkan.

Beberapa persoalan dasar wayfinding yang perlu diperhatikan pada area publik transportasi menurut Craig M. Berger (2005) diantaranya:

- Acknowledgment, yakni sebuah pemahaman yang harus dimiliki baik arsitek maupun desainer mengenai sign yang digunakan agar dapat memenuhi kebutuhan pengguna/pengunjung dalam mendapatkan informasi.

- Hierarchy, yaitu kondisi keterangan signage secara runut, dimulai dari identifikasi ruang lingkup luas (contoh: nama gedung), lalu dilanjutkan ke keterangan yang lebih spesifik (contoh: letak resepsionis, ruang tunggu, dll).

- Quantity, terkait dengan jumlahnya, yakni jumlah yang sedikit namun dengan memaksimalkan informasi di dalamnya merupakan cara terbaik dalam penggunaan wayfinding dan signage.

- Legibility, bisa berupa pertimbangan signage yang tidak hanya baik dari segi arsitektur, namun juga melihat dari segi komunikasi, bahwa signage tidak hanya harus terbaca dengan mudah, tetapi juga tidak mengganggu.

- Supplemental Component, yakni berupa pemasangan signage komersil/iklan yang sebaiknya disusun secara rapi dan dengan ukuran yang seragam. Faktor lainnya yaitu lighting, yang pada penerapannya harus disesuaikan dengan lingkungan sekitar serta legibility dari signage tersebut.

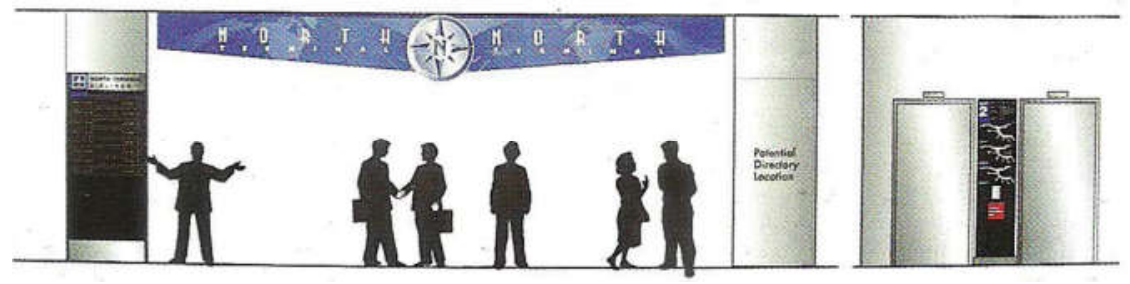

Gambar 1. Signage's Legibility Illustration

Sumber: Signage and Wayfinding Design

Craig M. Berger (2005) menyebutkan bahwa lokasi penempatan sign ditentukan oleh hasil analisa rute sirkulasi dan titik dimana terjadi decision point atau titik keputusan pengunjung pada suatu tempat. Untuk itu perlu adanya pengamatan kembali dari layout tapak proyek/tempat tersebut (penggambaran dari atas) yang kemudian dibuat rute sirkulasi serta decision point. Meskipun layout tapak dapat menjawab lokasi penempatan sign, perlu diingat bahwa penempatan secara vertikal juga sama pentingnya. Hal ini dapat terjadi pada proyek/tempat yang memiliki lantai bertingkat, yang juga memiliki banyak sirkulasi. Maka, hal tersebut dapat dianalisa melalui tampak potongan dari proyek/tempat tersebut sehingga 
penempatan secara vertikal juga dapat teratasi. Berikut adalah kriteria signage yang baik dalam hal penempatannya, yaitu:

- Ditempatkan segaris lurus dengan garis pandang dan pergerakan pengunjung

- Signage tersebut ditempatkan pada decision point

- Identification sign ditempatkan pada tempat tujuan agar pengunjung dapat memastikan apakah benar mereka telah berada di tempat yang dituju sebelumnya.

Peletakkan signage secara vertikal perlu diperhatikan letak ketinggian signage system serta ukuran font yang digunakan. Ketinggian yang baik dalam peletakkan signage system yaitu sebesar $10^{\circ}$ dari sudut pandang pengguna.

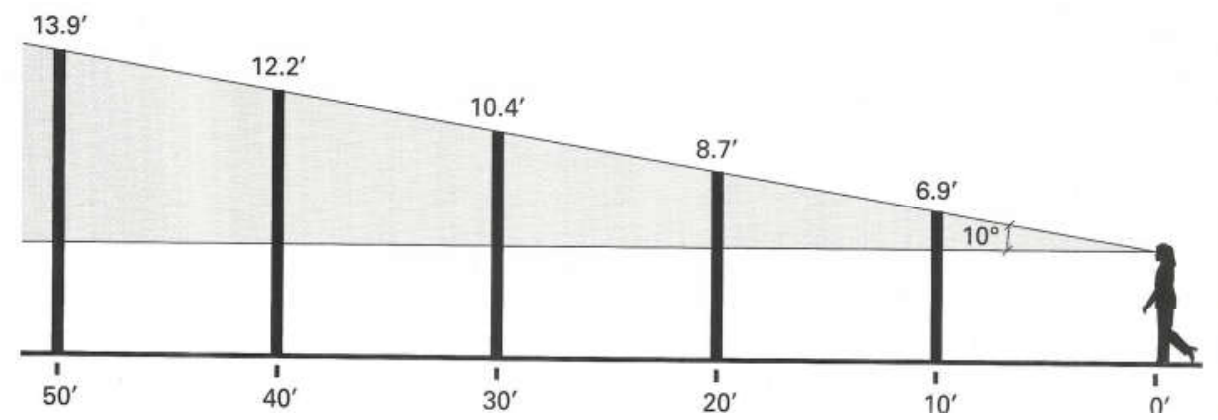

Gambar 2. Sudut Pandang $10^{\circ}$

Sumber: Signage and Wayfinding Design

Sementara itu, Weisman (1981) dikutip dari O’Neill (1991) mengembangkan empat variabel yang mempengaruhi wayfinding, dua diantaranya adalah penggunaan sign dan penomoran ruangan untuk identifikasi, dan konfigurasi denah. Hal ini diperkuat oleh pendapat Bronzaft dan Dobrow (1984) serta Nichols, Canete, dan Tuladahar (in press) yang dikutip dari O’Neil (1991) bahwa bentuk denah mempengaruhi kemudahan dan kesulitan dalam wayfinding, terutama pada sarana transportasi terkait kompleksitas konfigursi koridor yang dibentuk. Studi yang dilakukan O’Neill (1991) menunjukkan bahwa denah simetris mengurangi kompleksitas bentuk.

Studi tersebut juga menunjukkan bahwa jenis papan petunjuk yang berbeda berfungsi berbeda bergantung pada konteks dan kompleksitas denah. Tipe petunjuk (sign) yang digunakan dalam studi tersebut antara lain berupa teks dan grafis. O'Neill (1991) juga mengukur perilaku wayfinding seperti mundur kembali, berhenti dan melihat-lihat, serta kesalahan berbelok. Studi tersebut menunjukkan bahwa petunjuk berupa teks berfungsi lebih efektif daripada grafis dalam mengurangi kesalahan pengambilan keputusan saat mengambil jalan. Akan tetapi, petunjuk berupa grafis berfungsi lebih efektif ketika ditempatkan pada kondisi dimana tingkat perjalanan lebih penting daripada ketepatan informasi. Hal yang berlaku pada sarana-sarana transportasi. 


\section{Metoda Penelitian}

Penelitian ini merupakan penelitian campuran yakni kualitatif dan kuantitatif, dengan metode pengumpulan data, antara lain:

- Studi Literatur: studi standar fasilitas stasiun dari beberapa literatur.

- Observasi: observasi lapangan terhadap pola perilaku pengunjung mulai dari pintu masuk hingga tempat tujuannya untuk mengetahui alur perjalanan dan pemanfaatan sarana informasi visual oleh pengunjung, dan observasi titik-titik informasi strategis dan tidak strategis. Survey lapangan dilakukan terhadap tata letak dan organisasi ruang, serta peletakkan titik informasi.

- Dokumentasi: dilakukan pada area yang lobby Stasiun Bandung serta signage yang sudah digunakan pada lobhy Stasiun Bandung.

- Wawancara: dilakukan secara acak terhadap pengunjung di lobby Stasiun Bandung.

- Kuesioner: diberikan pada pengunjung dengan mengambil responden secara acak.

\section{Hasil \& Diskusi}

\subsection{Layout dan Sirkulasi}

Stasiun Bandung terbagi menjadi dua bagian, yakni Utara dan Selatan. Penelitian ini mengambil fokus studi di lobby pintu Utara Stasiun Bandung yang tersusun secara sentral dengan lobby sebagai pusat orientasi dan sebagai ruang utama. Tata ruang tampak pada gambar 3, yang menunjukkan posisi lobby dan jenis-jenis ruang di sekelilingnya.

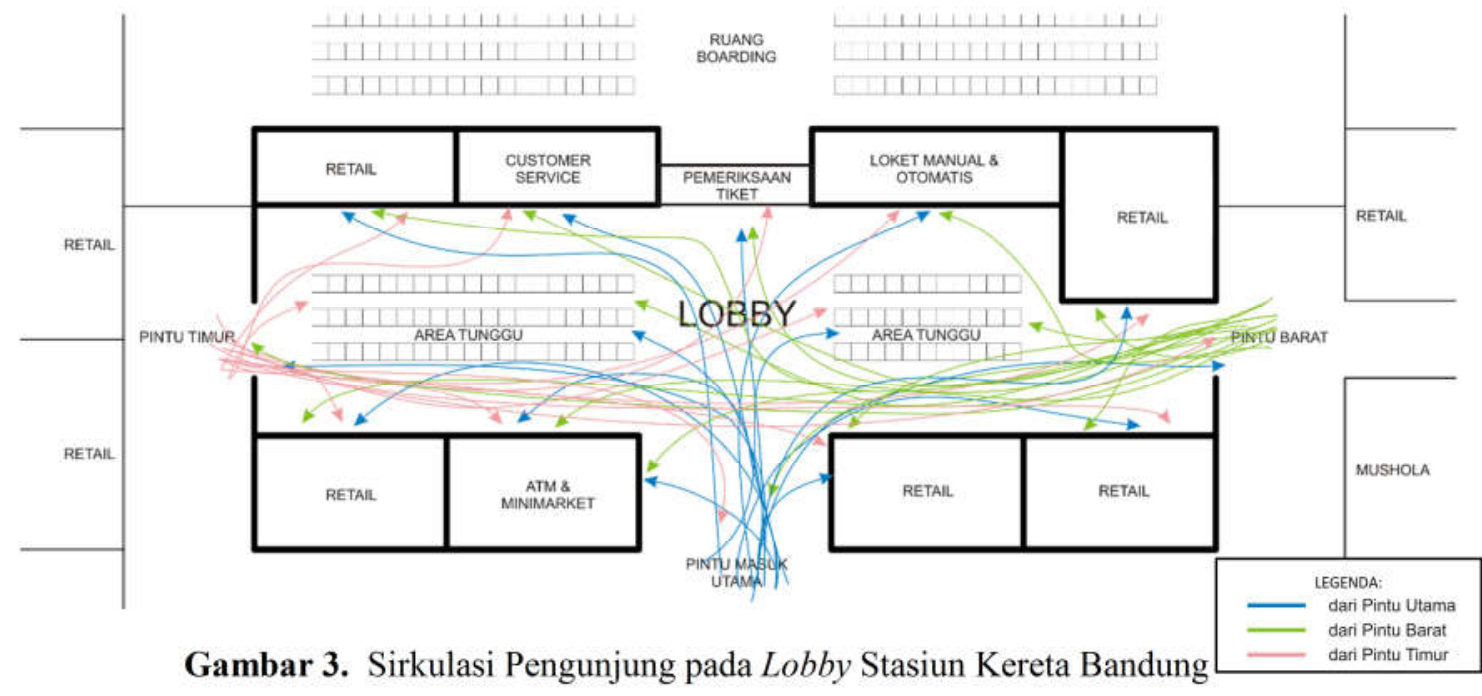

Denah Stasiun Utara bersifat memusat dengan lobby sebagai ruangan utama yang menghubungkan setiap ruangan di sekelilingnya. Area tunggu lobby merupakan area tunggu pengunjung yang membeli tiket, menukar tiket, mengantar, atau akan memasuki pintu pengecekan untuk berangkat. Sementara itu area tunggu bagi penjemput tidak disediakan khusus melainkan menunggu di area pintu timur dan barat.

Pintu masuk menuju lobby terdapat di bagian Barat, Timur, dan Utara dengan pintu Utara sebagai pintu utama. Akses Barat dan Timur di samping peron merupakan pintu keluar 
peron yang digunakan oleh penumpang stasiun yang baru tiba dari peron. Koridor pintu Timur dan Barat digunakan oleh penjemput untuk menjemput penumpang yang baru tiba. Pintu keluar yang dibuka hanya satu pada setiap kesempatan, bisa di Barat atau di Timur, tidak pernah dibuka bersamaan. Akses ini juga seringkali tidak dilengkapi petunjuk sehingga pihak penjemput seringkali kesulitan menemukan letak akses keluar peron untuk menunggu penumpang tiba.

Asal pengunjung yang masuk ke lobby dari pintu Timur berasal dari arah area parkir motor. Sedangkan asal pengunjung yang masuk dari pintu Utara yaitu pengunjung yang berasal dari arah area parkir mobil. Lobby agak jarang diakses dari pintu Barat.

Dari pintu masuk utama Utara, arah yang dituju diantaranya area tunggu, loket, pemeriksaan tiket, customer service, atm dan minimarket, retail. Sedangkan kemungkinan arah tujuan pengunjung yang berasal dari pintu Barat, diantaranya yakni ke area tunggu, customer service, atm dan minimarket, retail, keluar melalui pintu masuk utama. Arah tujuan pengunjung yang berasal dari pintu Timur diantaranya area tunggu, loket, pemeriksaan tiket, customer service, atm dan minimarket, retail, maupun keluar melalui pintu masuk utama.

Berdasarkan observasi, pengunjung yang sudah mengenal situasi stasiun tidak banyak menunjukkan perilaku mundur kembali (backtracing), berhenti dan melihat-lihat, ataupun kesalahan berbelok. Perilaku tersebut lebih tampak pada pengunjung yang baru mengenal atau belum terlalu mengenal situasi stasiun. Perilaku yang cukup sering terlihat adalah berhenti dulu dan melihat-lihat (stopping and looking).

Konfigurasi denah stasiun yang bersifat memusat dan simetris sedikit banyak memudahkan pengunjung dalam mengenali ruang stasiun, sesuai dengan studi yang dilakukan O’Neill (1991). Konfigurasi denah memusat dengan lobby sebagai ruang utama yang menghubungkan ruang-ruang lain memudahkan pengunjung menemukan wayfinding dan mengurangi ketersesatan pengunjung dalam ruang.

\subsection{Penempatan Papan Petunjuk (Signage System)}

Lokasi penempatan signage system perlu ditentukan dengan memperhatikan konteks fungsi bangunan. Untuk menentukan lokasi signage system terutama jenis penunjuk arah ruangan (wayfinding), yang dapat berfungsi dengan baik dari segi dua dimensi atau secara layouting, maka perlu ditentukan titik keputusan (decision point). Decision point ini merupakan titik dimana pengguna menentukan untuk ke arah mana ia akan pergi dan di titik inilah perlu diletakkan sygnage system agar informasi tersampaikan secara optimal. Letak dari decision point dari lobby Stasiun Kereta Bandung ini dapat ditentukan berdasarkan sirkulasi pengunjung. Berikut adalah titik lokasi ideal signage system yang dikenali pada lobby Stasiun Kereta Bandung: 

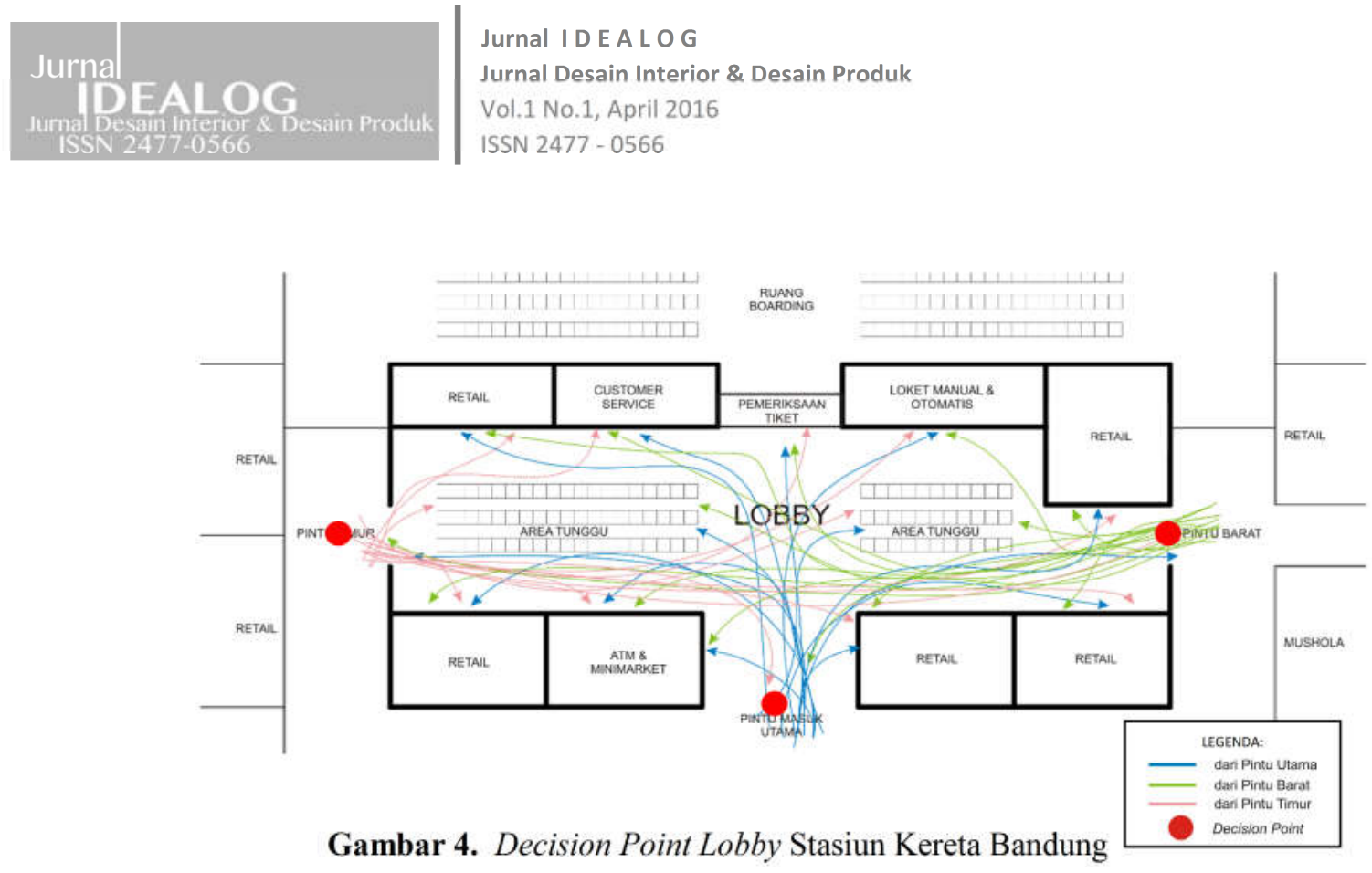

Pada lobby Stasiun Kereta Bandung terdapat beberapa Papan Petunjuk (Signage System) yang sudah terpasang di beberapa titik. Signage System tersebut ada yang berupa penunjuk arah ruangan (wayfinding) dan penamaan ruang (identification sign). Berikut posisi perletakkan wayfinding dan identification sign pada lobby Stasiun Bandung saat ini:

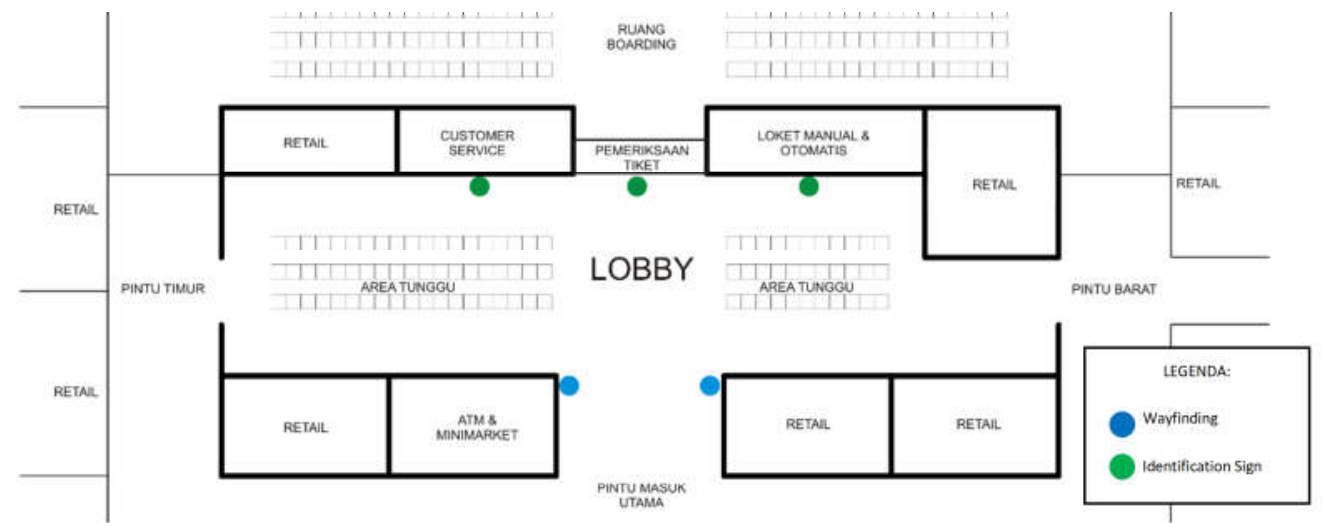

Gambar 5. Letak Wayfinding dan Identification Sign Stasiun Kereta Bandung

- Penunjuk Arah Ruangan (Wayfinding)

Untuk jenis penunjuk arah ruangan (wayfinding) pada lobby Stasiun Kereta Bandung, papan petunjuk ini terbagi dua dan dipasang di sisi yang berbeda dan saling bersebrangan (gambar 6a.). Kedua wayfinding ini dipasang pada ketinggian 4 meter dan berjarak 5 meter dari pintu masuk utama. Masing-masing dari papan petunjuk ini menunjukan ruang yang berbeda termasuk arahnya. Contohnya, pada papan petunjuk yang dipasang di sebelah barat menunjukkan arah ruangan yang berada di timur (gambar 6b.), begitupun sebaliknya, dimana petunjuk yang dipasang di sebelah timur menunjukkan arah ruangan yang berada di barat (gambar 6c.) 


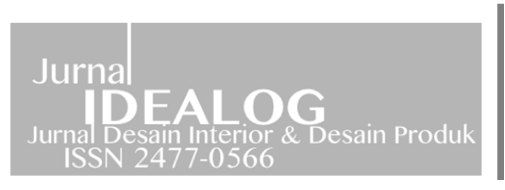

b.

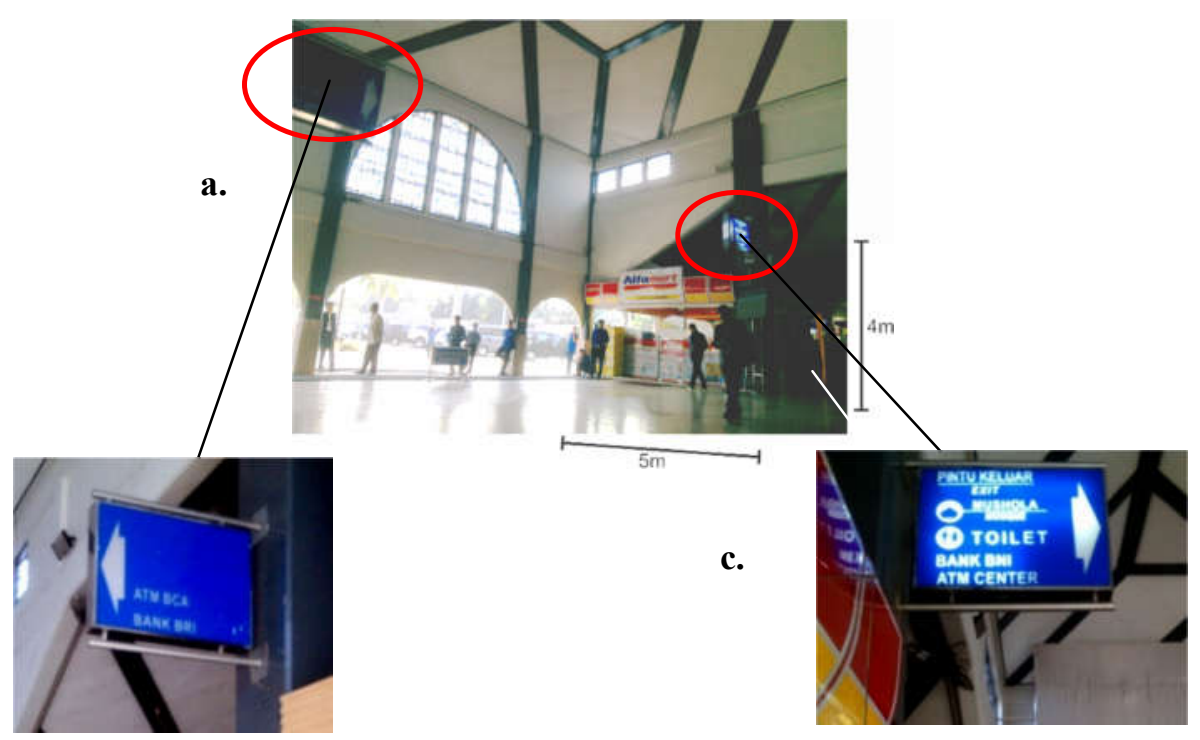

Gambar 6. Penunjuk Arah Ruangan (Wayfinding)

Dengan jarak dari pintu masuk yakni 5 meter, maka dengan perhitungan sudut pandang nyaman pengguna sebesar $10^{\circ}$, maka signage ini semestinya memiliki jarak ketinggian sebesar 2,2 meter dari lantai, 1,8m lebih rendah dari posisi saat ini. Jenis huruf (font) yang digunakan sudah cukup jelas dan tidak berlebihan, namun ukuran font yang digunakan pada wayfinding ini cenderung tidak konsisten, menggunakan beberapa ukuran font yang berbeda pada satu signage. Hal ini cenderung membingungkan karena seakan memprioritaskan suatu tempat.

Pada signage gambar 6.c. juga tampak dua jenis sign pada satu papan, yaitu sign berupa teks dan grafis. Sign hibrid ini dapat menciptakan kebingunan pada pembacanya dan menjadi kurang efektif karena fungsi grafis cenderung terabaikan. Pada sign hibird, pembaca lebih berkecenderungan untuk membaca informasi teks. Sesuai dengan rekomendasi O'Neill (1991) bahwa pada sarana transportasi lebih diperlukan petunjuk pengarah berupa grafis untuk memudahkan perjalanan, meskipun tingkat akurasi informasi kurang, maka seharusnya petunjuk pengarah berupa grafis lebih banyak dimunculkan tanpa menghadirkan teks di sampingnya.

- Penamaan Ruang (Identification Sign)

Untuk jenis penamaan ruang pada lobby Stasiun Kereta Bandung, terdapat beberapa signage system yang sudah terpasang, diantaranya penamaan ruang loket (gambar 7a.), customer service (gambar 7b.), dan pemeriksaan tiket (gambar 7c.). Penempatan tiga identification sign ini diletakkan pada ketinggian 3 meter, dengan menggunakan ukuran, font, warna, dan desain yang berbeda satu sama lain. 


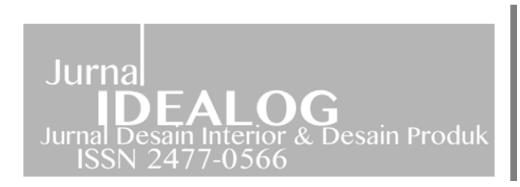

a.

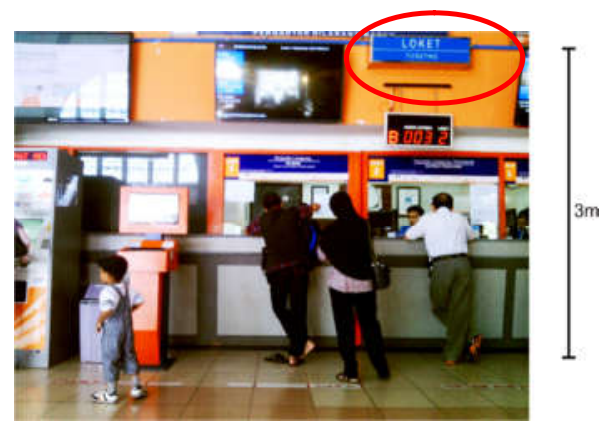

b

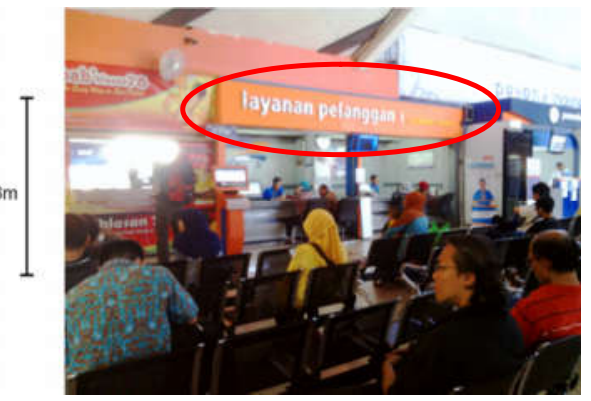

C

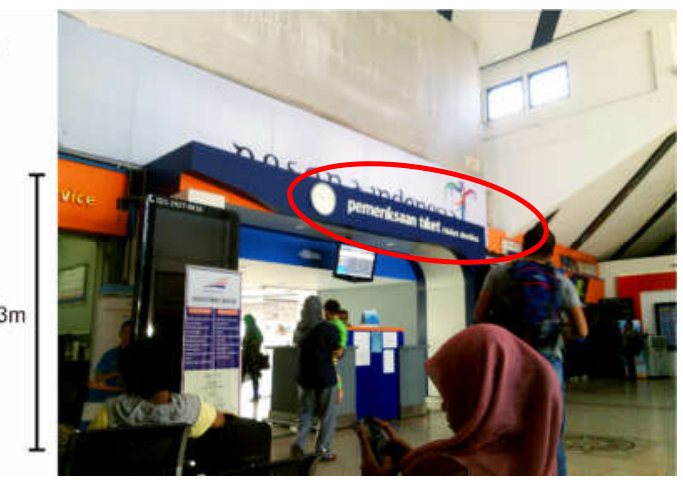

Gambar 7. a, b, c Penamaan Ruang (Identification Sign)

Dengan jarak ketinggian penamaan 3 meter, maka dengan perhitungan sudut pandang nyaman pengguna sebesar $10^{\circ}$, maka signage ini seharusnya dapat terlihat jelas pada jarak 6,8 meter secara horizontal. Jenis huruf (font) yang digunakan sudah cukup jelas dan tidak berlebihan, serta warna yang digunakan cukup dapat dilihat jelas oleh mata.

Penilaian kinerja wayfinding dilakukan terhadap 21 responden dengan mengambil sampel acak pengunjung dan penumpang di stasiun. Adapun kriteria yang digunakan berdasarkan kriteria sign yang disusun oleh Sumbo Tinarbuko (2008). Hasil kuisioner adalah sebagai berikut:

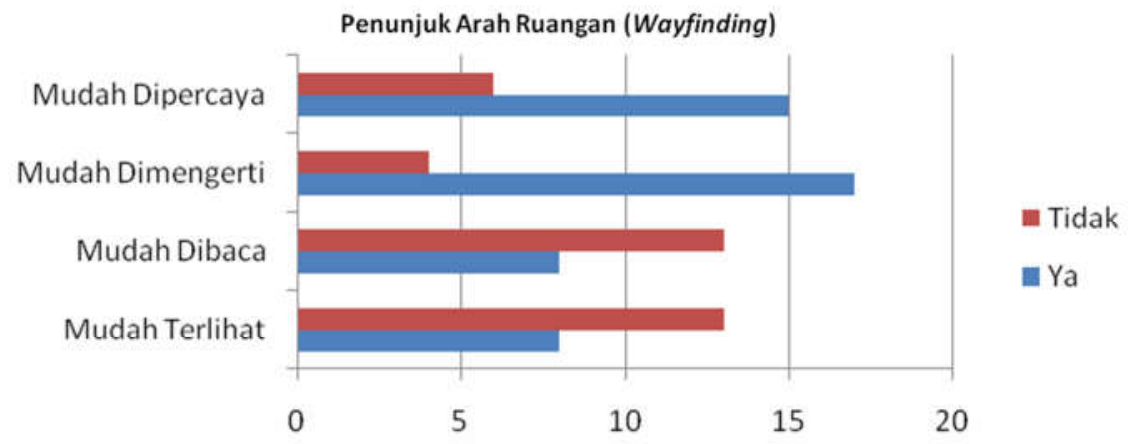

Diagram 1. Grafik penilaian terhadap Penunjuk Arah Ruangan 
Dari 21 responden, sebanyak 15 orang menyatakan bahwa wayfinding stasiun mudah dipercaya, 17 orang menyatakan wayfinding mudah dimengerti, 8 orang menyatakan wayfinding mudah dibaca, dan 8 orang menyatakan bahwa wayfinding mudah terlihat.

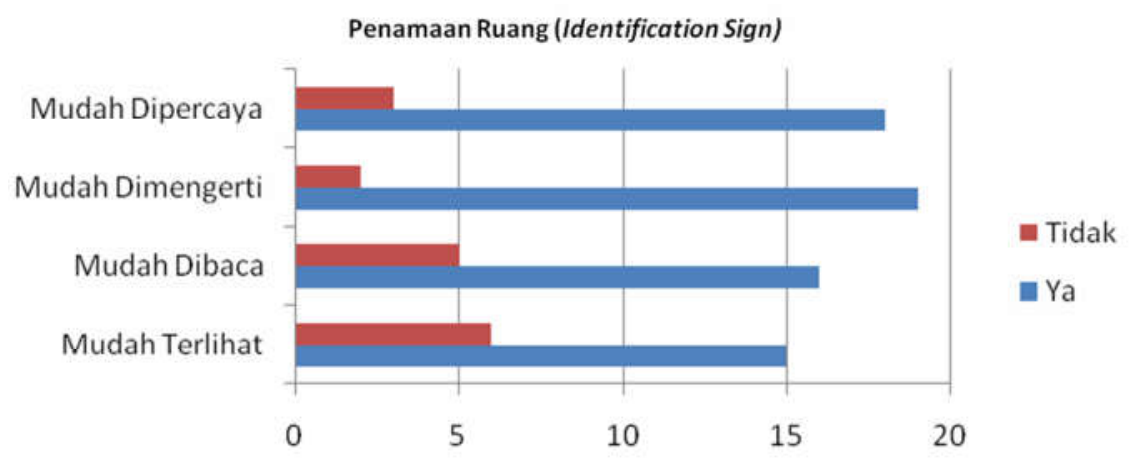

Diagram 2. Grafik penilaian terhadap penamaan ruang

Di sisi lain, dilakukan penilaian identification sign yang dilakukan terhadap 21 responden yang sama terkait kriteria sebuah signage. Hasilnya, sebanyak 18 orang menyatakan bahwa identification sign mudah dipercaya, 19 orang menyatakan identification sign mudah dimengerti, 16 orang menyatakan identification sign mudah dibaca, dan 15 orang menyatakan bahwa identification sign mudah terlihat.

Signage merupakan elemen yang dinilai tidak memenuhi kriteria baik oleh responden. Responden menilai bahwa signage di stasiun belum cukup baik dari segi perletakkan, ukuran, hingga desain yang digunakan. Berikut adalah beberapa saran terkait signage system pada lobby Stasiun Kereta Bandung, diantaranya:

- dibenahi perletakkannya karena kurang strategis (19\% responden)

- signage system yang ada sekarang ini dibuat lebih menarik dari segi desain dan memiliki konsep yang sama sehingga tidak terlihat 'beragam' ( $42 \%$ responden)

- ukuran papan signage serta font yang digunakan diperbesar lagi (52\% responden)

- diberi cahaya tambahan agar lebih terang dan terlihat (4\% responden).

Dari hasil kuesioner tersebut yang diambil dari 21 reponden, dapat disimpulkan bahwa responden lebih tidak puas terhadap penunjuk arah ruangan (wayfinding) daripada terhadap identification sign pada lobby Stasiun Kereta Bandung. Hal ini terlihat dari grafik penilaian wayfinding bahwa 13 dari 21 responden, atau 61,9\%, yang menyatatakan bahwa wayfinding sulit terlihat dan sulit terbaca. Hal ini berbanding terbalik dengan hasil kuisioner terhadap identification sign bahwa rata-rata 17 dari 21 responden, atau 80,95\%, menyatakan bahwa identification sign dapat dipercaya, mudah dimengerti, mudah terlihat, dan mudah dibaca. 


\section{Kesimpulan}

Pada area lobby Stasiun Kereta Bandung, terdapat beberapa papan petunjuk (signage system) yang sudah terpasang di beberapa titik. Signage system tersebut ada yang berupa penunjuk arah ruangan (wayfinding) dan penamaan ruang (identification sign). Berdasarkan hasil observasi, wawancara dan kuesioner terhadap sejumlah responden, disimpulkan bahwa signage yang ada sekarang ini belum efektif dari segi perletakannya maupun dari segi desain dan pemanfaatan jenis sign. Kehadiran sign hibrid (campuran teks dan grafis) seperti pada gambar 6.c. membuat desain sign tidak sesuai standar yang menimbulkan perbedaan ukuran font dan ketidakjelasan informasi jika dibaca dari jarak tertentu sehingga membuat kebingungan pada pembaca. Selain itu, beberapa sign ditempatkan pada jarak yang terlalu tinggi secara vertikal sehingga tingkat keterbacaan rendah.

Perlu dilakukan penataan ulang terhadap signage di Stasiun Bandung sisi Utara baik dari segi layouting maupun penempatan vertikal, yaitu dengan cara menentukan decision point berdasarkan hasil analisa sirkulasi seperti tampak pada gambar 4, serta memperhatikan sudut pandang user secara vertikal, sehingga dapat ditentukan ketinggian yang tepat untuk penempatan vertikal. Penggunaan sign hibrid harus dihindari dan lebih memanfaatkan sign jenis grafis untuk efektivitas pemberian informasi pada pengunjung sesuai dengan kebutuhan stasiun sebagai sarana transportasi yang mementingkan tingkat (kecepatan) perjalanan ketimbang akurasi informasi, sesuai dengan rekomendasi O’Neill (1991). Hal tersebut perlu dilakukan agar stasiun dapat berfungsi secara lebih optimal.

\section{Daftar Pustaka}

[1] Berger, Craig. Wayfinding, Designing and Implementing Graphic Navigational System, Roto Vision, Switzerland. (2005).

[2] Calori, Chris. Signage and Wayfinding Design, John Wiley \& Sons inc., New Jersey, (2007).

[3] Karimi, Hassan A. Indoor Wayfinding and Navigation, CRC Press, Boca Raton, (2015).

[4] Peraturan Menteri Perhubungan Republik Indonesia, Nomor: PM. 47 Tahun 2014, Standar Pelayanan Minimum untuk Angkutan Orang dengan Kereta Api. (2014).

[5] O’Neill, Michael J. Effects of Signage and Floor Plan Configuration on Wayfinding Accuracy. Environment and Behavior Journal, Vol. 23 No. 5. (1991). Available at: http://eab.sagepub.com Accessed: 2016-04-21

[6] Djuliansyah, Irpan. Perancangan Sign System Stasiun Televisi TVRI Jawa Barat, Available at http://elib.unikom.ac.id/gdl.php?mod=browse\&op=read\&id=jbptunikompp-gdlirpandjuli-29909 Accessed: $2015-10-01$.

[7] Hermawan, Joni. Perancangan Sign System Universitas Komputer Indonesia (UNIKOM), Available at 


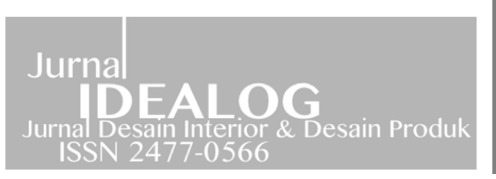

Jurnal I D E A L O G

Jurnal Desain Interior \& Desain Produk

Vol.1 No.1, April 2016

ISSN 2477 - 0566

http://elib.unikom.ac.id/gdl.php?mod=browse\&op=read\&id=ibptunikompp-gdljonihermaw-26663 Accessed: 2015-10-01.

[8] Hutasoit, Ruth Dina Mentari \& Putra, I Dewa Alit Dwija. Re-designing Sign System in Kiaracondong Railway Station Bandung, Available at

https://www.academia.edu/10214648/redesigning sign system in kiaracondong rail way station bandung Accessed: 2015-09-19. 